\title{
Incumplimiento de las normas de bioseguridad por personal de salud aun en tiempos de la Covid 19
}

\author{
Non-compliance with biosafety regulations by health personnel even in times of Covid 19
}

\section{Sr. Editor:}

El término bioseguridad está relacionado con las medidas que se toman para salvaguardar la vida y salud a nivel personal, de grupo y del medio ambiente ${ }^{(1,2)}$. En el contexto de la pandemia por la Covid-19, el riesgo que el personal de salud enfrenta diariamente en su ambiente de trabajo es evidente, en especial por que el SARS-CoV-2 es de fácil transmisión al contacto con material contaminado. Por ello los trabajadores de salud en general son susceptibles a contraer y trasmitir enfermedades de diferente índole entre ellas las respiratorias, por lo que se deben tomar medidas de educación e intervenciones para la mejora del conocimiento/actitudes y prácticas adecuadas ${ }^{(3)}$.

La capacitación en bioseguridad y control de infecciones, debe brindarse a todo el personal de salud de manera regular y se debe ejercer periódicamente ${ }^{(2)}$. Esto es importante para que el personal de salud en el Perú conozca las medidas que se deben tomar, ya que el conocimiento es un factor importante e influyente en la protección y prevención de enfermedades, reduciendo los riesgos biológicos, optimizando las decisiones de los profesionales ${ }^{(3)}$.

La Directiva 2000/54/CE (protección de los trabajadores contra los riesgos relacionados con la exposición a agentes biológicos en el trabajo), es una de las principales regulaciones de la Unión Europea en bioseguridad; establece que, si un trabajador sufre una infección o enfermedad como resultado de la exposición en el lugar de trabajo, se deben ofrecer pruebas de diagnóstico, interviniendo también a los contactos, y en ese sentido pudiera aplicarse para la contención de la Covid-19, complementándose con los procedimientos de desinfección del área ${ }^{(1)}$. En este sentido los hospitales deberían contar con los recursos y capacitación para ejecutar dichos procedimientos.

Un estudio previo menciona que los mandiles y ropas de uso médico con frecuencia se usan tanto en las salas de hospitalización, en los ambientes de trabajo, y algunos inclusive en sus automóviles, vehículos de transporte público, cafeterías, restaurantes y casas, causando la diseminación de bacterias multi drogo resistentes y virus como el SARS-CoV-2 ${ }^{(4)}$. Estas malas prácticas en las que se incluye el no lavado de manos y uso indebido de celulares deben erradicarse comenzando con un proceso de disminución progresiva de las malas prácticas y estricto apego a las normas de bioseguridad para enfrentar la pandemia de la Covid19 de manera más adecuada. Lamentablemente, como no existe normativa en el Ministerio de Salud del Perú que restrinja el uso de la ropa hospitalaria fuera de los establecimientos de salud, es frecuente encontrar personal de salud y estudiantes de las diferentes carreras de salud, con estos trajes en diferentes lugares púbicos como buses, automóviles, supermercados y restaurantes.

La implementación de los procedimientos en bioseguridad, deben aplicarse durante la manipulación de material contaminado que contiene agentes

\footnotetext{
Facultad de Ciencias de la Salud, Área de Investigación, Universidad Privada del Norte. Lima, Perú.

Facultad de Ciencias de la Salud, Carrera de Obstetricia, Universidad Privada del Norte. Lima, Perú.

Maestro en Biología Molecular

Maestra en Docencia e Investigación
} 
altamente infecciosos, como muestras de diagnóstico, pacientes e indumentaria del personal de salud ${ }^{(2)}$. Lo recomendable es empezar a implementar desde ahora dichas estrategias, debiendo ser un punto de inflexión en nuestro sistema de salud ahora en tiempos de la Covid-19 como se vienen implementando en ciertos países donde se produjeron accidentes relacionados a la bioseguridad ${ }^{(5)}$.

Concluimos que es un deber del personal de salud aplicar las normas de bioseguridad con mayor razón en tiempos de Covid-19 y evitar infecciones innecesariamente.

\section{Jesús Rojas Jaimes ${ }^{1, a}$, Lily Carmnina Callalli ${ }^{2, b}$}

\section{Correspondencia:}

Jesús Rojas Jaimes

Teléfono: (511) 6184660

Correo electrónico: jesus.rojas.jaimes@gmail.com

\section{REFERENCIAS BIBLIOGRÁFICAS}

1. Bielecka-Oder A. Safety and security regulations against biological threats. En: Radosavljevic V, Banjari I, Belojevic G. (Editores). Defence Against Bioterrorism: Methods for Prevention and Control. Belgrado Springer; 2017.p. 25-42.

2. Puro V, Fusco FM, Schilling S, et al. For the European Network for Highly Infectious Diseases. Biosecurity measures in 48 isolation facilities managing highly infectious diseases. Biosecur Bioterror. 2012; 10(2):208-214. doi: 10.1089/bsp.2011.0098

3. Mejia CR, Jimenez-Meza Y, Chacon JI, et al. Bioseguridad respiratoria practicada en ambientes laborales de catorce ciudades peruanas: Estudio piloto. Rev Asoc Esp Espec Med Trab. 2019; 28(2):117-125.

4. Llanos-Cuentas A. Transmisión de infecciones nosocomiales por el personal de salud. Rev Med Hered. 2016; 27(2):73-74.

5. Zelicoff A P. Laboratory biosecurity in the United States: Evolution and regulation. In Ensuring National Biosecurity. Academic Press. 2016; 1:1-22

Recibido: 31/10/2020

Aceptado: 29/12/2020 